\title{
Methamphetamine Influences on Recognition Memory: Comparison of Escalating and Single-Day Dosing Regimens
}

\author{
Annabelle M Belcher', Erin M Feinstein', Steven J O'Dell' and John F Marshall*,' \\ 'Department of Neurobiology and Behavior, University of Califormia, Irvine, CA, USA
}

\begin{abstract}
Methamphetamine (mAMPH) is an addictive drug that produces memory and recall impairments in humans. Animals subjected to a binge $\mathrm{mAMPH}$ dosing regimen that damages brain dopamine and serotonin terminals show impairments in an object recognition (OR) task. Earlier research demonstrated that preceding a single-day $\mathrm{mAMPH}$ binge regimen with several days of increasing $\mathrm{mAMPH}$ doses greatly attenuates its neurotoxicity in rats. The escalating dose (ED) paradigm appears to mimic the human pattern of escalating drug intake. The current aim was to test whether an ED plus binge mAMPH regimen produces OR impairments. In addition to its translational value, this experiment helps address whether monoaminergic neurotoxicity accounts for OR impairments seen after mAMPH administration. To further address this issue, a separate experiment investigated both OR impairments and monoamine transporter integrity in groups of rats treated with a range of $\mathrm{MAMPH}$ doses during a single day. An ED mAMPH regimen attenuated the acute hyperthermic response to the subsequent $\mathrm{mAMPH}$ binge and prevented the OR impairments and reductions in $\left[{ }^{125}\right]$ RTI-55 binding to monoamine transporters in striatum, hippocampus $(\mathrm{HC})$, and perirhinal cortex $(\mathrm{pRh})$ that otherwise occur I week after the mAMPH binge. Single-day $\mathrm{mAMPH}$ regimens $(4 \times I \mathrm{mg} / \mathrm{kg}$ to $4 \times 4 \mathrm{mg} / \mathrm{kg}$, s.c.) dose-dependently produced acute hyperthermia and, I week postmAMPH, produced dose-dependent impairments in OR and reductions in monoamine transporter binding. The OR impairments of single-day mAMPH-treated rats correlated with monoaminergic transporter loss in ventral caudate-putamen, HC, and pRh. In aggregate, these findings suggest a correspondence between $\mathrm{mAMPH}$-induced monoaminergic injury and the resulting OR deficits.

Neuropsychopharmacology (2008) 33, I453- |463; doi: I 0. I038/sj.npp. I30 I 5 I0; published online 18 July 2007
\end{abstract}

Keywords: amphetamines; DAT; SERT; novelty detection; neurotoxicity; object recognition

\section{INTRODUCTION}

Methamphetamine (mAMPH) is a widely abused synthetic psychostimulant that produces a broad spectrum of behavioral effects. The drug's strong reinforcing qualities, its long-lasting effects, as well as the ease with which it can be manufactured has produced an epidemic of illicit drug use. A growing literature suggests that mAMPH may result in long-term cognitive deficits in humans. Clinically, current and abstinent mAMPH users show impairments in various tests of verbal and non-verbal memory, executive function, attention, and motor performance (Volkow et al, 2001; Simon et al, 2002; Thompson et al, 2004; Gonzalez et al, 2004).

For many years, animal models of mAMPH's effects have principally employed single-day, repeated high-dose ('binge') mAMPH regimens. Animals previously exposed to these dosing regimens show impairments in both motor

\footnotetext{
*Correspondence: Dr JF Marshall, Department of Neurobiology and Behavior, University of California, Irvine, 2215 Bio Sci II, CA 92697-4550, USA, Tel: + I 949824 4722; Fax: + I 9498242447 , E-mail: jfmarsha@uci.edu

Received 23 February 2007; revised 10 May 2007; accepted 12 June 2007
}

performance tasks (Walsh and Wagner, 1992) and an appetitive maze sequential learning task (Chapman et al, 2001), and have mild spatial memory impairments (Friedman et al, 1998; however, see Schröder et al, 2003). More recently, several reports (Bisagno et al, 2002; Schröder et al, 2003; Belcher et al, 2005) have shown that rats exposed to bingeing doses of mAMPH are impaired in a task of novelty detection object recognition (OR).

However, several researchers have argued that the animal model of single-day binge mAMPH administration fails to capture an important feature of chronic stimulant abuse; namely, the gradual escalation of mAMPH doses that is typically seen as drug use progresses. From this perspective, the inclusion of an escalating mAMPH component in experimental studies more appropriately models the ramping up of mAMPH use in humans. Clearly, the degree of mAMPH-induced CNS injury depends on the pattern of dosing. Single-day binge doses of mAMPH, when sufficiently high, can produce long-lasting neurotoxic damage to the dopaminergic (Seiden et al, 1975; Ellison et al, 1978) and serotonergic systems (Ricaurte et al, 1980; Axt and Molliver, 1991), as well as degeneration of cells in somatosensory cortex (Commins and Seiden, 1986; O'Dell and Marshall, 2000). However, binge mAMPH-related increases in behavioral stereotypy and body temperature, as well as 
subsequent reductions in dopamine content and dopamine transporter (DAT) binding, are attenuated when the binge dosing regimen is preceded by a multi-day escalating dose (ED) regimen of mAMPH administration (Segal et al, 2003). In addition to approximating the pattern of increasingly higher mAMPH doses that human abusers report, this ED regimen was used in the present study to test further the relationship between mAMPH-induced OR impairments and neurotoxicity.

The purpose of the present study was to evaluate whether animals exposed to an ED plus binge regimen of mAMPH (13 days of EDs of mAMPH followed by a single-day, binge administration of $\mathrm{mAMPH}$ ) would exhibit impairments in the OR task. Additionally, the fact that escalating mAMPH regimens attenuate binge mAMPH-induced neurotoxicity allowed us to investigate the role of neurotoxicity in the production of cognitive deficits. To further address this question, a second experiment was conducted in which animals were administered various mAMPH doses (which were either neurotoxic or non-neurotoxic) during a single day and then tested for OR. All tests of OR performance were conducted 1 week after the final drug treatments. In each experiment, animals were euthanized 1 week following OR testing, and their brains were processed for [ $\left.{ }^{125} \mathrm{I}\right] \mathrm{RTI}-55$ binding autoradiography of dopaminergic and serotonergic transporters to assess monoaminergic terminal integrity.

\section{MATERIALS AND METHODS}

\section{Subjects}

Adult male Sprague-Dawley rats (275-300 g) were obtained from Charles River Laboratories (Hollister, CA) and individually housed, with food and water ad libitum, under a standard 12-h light/12-h dark cycle (lights on 0700-1900 h) at a temperature of $22^{\circ} \mathrm{C}$. The protocol for this research was approved by the Institutional Animal Care and Use Committee of the University of California, Irvine. Acquisition, maintenance, handling, procedures, and care of the animals were in accord with the NIH Guide for the Care and Use of Laboratory Animals (NIH Guide, Vol. 25, no. 28, 1996).

\section{Drug Treatments}

Rats were treated with $(+)$ mAMPH hydrochloride (Sigma, St Louis, MO) in two separate experiments. All drug and vehicle injections were administered at a volume of $1 \mathrm{ml} / \mathrm{kg}$, and doses are expressed as the free base.

In Experiment 1, animals were given one of four treatments: group MA/MA $(N=14)$ received a 13-day mAMPH ED regimen followed by a mAMPH binge on day 14; group SA/MA $(N=12)$ received saline for 13 days followed by a mAMPH binge; group mAMPH binge $(N=14)$ received only mAMPH during the binge regimen; and group SAL binge $(N=11)$ received only saline during the binge regimen. The $\mathrm{ED}$ regimen consisted of three injections per day of SAL or mAMPH in gradually increasing doses for 13 days, and all injections during the ED regimen were administered in the animals' individual home cages. mAMPH or SAL injections were administered $3 \mathrm{~h}$ apart, and the $\mathrm{mAMPH}$ dosages began at $0.1 \mathrm{mg} / \mathrm{kg}$ (s.c.) and increased by $0.1 \mathrm{mg} / \mathrm{kg}$ with every injection, so that on the 13th day, the animals received $3.9 \mathrm{mg} / \mathrm{kg}$. On day 14 , animals in all four groups were placed into Plexiglas boxes $(40 \times 40 \times 38 \mathrm{~cm} \mathrm{high})$ in groups of six to eight animals per treatment group and were given four subcutaneous injections of either $4 \mathrm{mg} / \mathrm{kg} \mathrm{mAMPH}$ or saline at 2 -h intervals (binge regimen). These injections took place in a room distinct from the animals' holding room. To determine the acute effects of mAMPH administration, and because mAMPH-induced hyperthermia is strongly correlated to mAMPH-induced neuronal damage (Bowyer et al, 1992, 1994), rectal temperatures were measured $1 \mathrm{~h}$ after each injection. Animals whose core temperatures reached $41^{\circ} \mathrm{C}$ or higher, or who lost postural support, were separated from the group and were cooled with ice water for $15 \mathrm{~min}$. Eight of the animals given $4 \times 4 \mathrm{mg} / \mathrm{kg}$ mAMPH (four each in groups SA/MA and mAMPH binge) succumbed to complications associated with hyperthermia, and are not included in any of the analyses.

In Experiment 2, the mAMPH binge regimen was administered as described in Experiment 1, using four injections of $4 \mathrm{mg} / \mathrm{kg}(N=27), 3 \mathrm{mg} / \mathrm{kg} \quad(N=24), 2 \mathrm{mg} / \mathrm{kg}$ $(N=14), 1 \mathrm{mg} / \mathrm{kg}(N=11)$, or saline (SAL; $1 \mathrm{ml} / \mathrm{kg}, N=40)$ at 2-h intervals. Three of the rats given the $4 \mathrm{mg} / \mathrm{kg} \mathrm{mAMPH}$ dose succumbed to complications associated with hyperthermia, and are not included in any of the analyses. Injections were given in Plexiglas boxes identical to those used for Experiment 1, and were treated in a room distinct from the animals' holding room.

\section{Novel OR}

One week after SAL or drug treatment, the animals were exposed to a novelty preference task of OR (Ennaceur and Delacour, 1988; Ennaceur and Aggleton, 1997; Mumby et al, 2002; Winters and Bussey, 2005). The OR task required that the rats recall which of two small objects they had previously been exposed to. The task took place in a large circular Plexiglas open field $(50.8 \mathrm{~cm}$ high, $44.45 \mathrm{~cm}$ in diameter), the outside walls of which were covered with contact paper. A $15 \mathrm{~W}$ lamp placed $30 \mathrm{~cm}$ above the apparatus provided the only illumination in the room. Six days after the last treatment with mAMPH or SAL, a habituation session was begun. Animals were placed individually into the arena and were allowed to freely explore for $3 \mathrm{~min}$. Twenty-four later, the OR task was conducted by placing individual rats for $3 \mathrm{~min}$ into the field, in which two identical objects (objects A1 and A2) were positioned in two adjacent corners, $10 \mathrm{~cm}$ from the walls (familiarization phase, FAM). In a short-term memory (STM) test given $90 \mathrm{~min}$ after familiarization, the rats explored the open field for $3 \mathrm{~min}$ in the presence of one familiar (A) and one novel (B) object. Objects were made of glass, plastic, and metal and were chosen after determining, in preliminary experiments with other animals, that they were equally preferred. Between each trial, both the openfield arena and the objects were washed with $95 \%$ ethanol solution. All sessions were videotaped, and an experimenter blind to treatment condition analyzed the OR behavior. Exploration was defined as sniffing or touching the object with the nose; sitting on the object was not considered exploration. Object placement was counterbalanced so that half of the animals in each treatment group saw the novel 
object on the left side (relative to the animal's starting position) of the open-field arena, and the other half saw the novel object on the right side of the arena. An exploration quotient (EQ) was calculated for each animal as $\left(T_{B}\right) \div$ $\left(T_{A}+T_{B}\right)$, where $T_{A}=$ time spent exploring the object $A$ and $T_{B}=$ time spent exploring the object $B$ (Ennaceur and Delacour, 1988). EQ scores were calculated for the FAM phase, with $T_{B}$ assignment dependent on the side of the novel object during the STM test. An EQ score of 50\% indicates chance performance (ie, zero discrimination between the two objects at either the FAM or STM phase). Animals that did not explore the objects for a minimum of $10 \mathrm{~s}$ in either the FAM phase or the STM phase were excluded from the analysis.

\section{Quantification of 5-HT and DA Transporters}

One week after completion of the last behavioral test, the rats were killed, and their brains were removed and frozen at $-20^{\circ} \mathrm{C}$ for use in autoradiography. Twenty micrometerthick coronal sections were cut in a cryostat at the levels of the striatum and dorsal hippocampus (HC), and sections were incubated with either $19 \mathrm{pM}$ (in Experiment 1) or $24 \mathrm{pM}$ (in Experiment 2) [ $\left.{ }^{125} \mathrm{I}\right] \mathrm{RTI}-55$ for autoradiographic localization of DAT in the striatum and serotonin transporter (SERT) in the HC and perirhinal cortex (pRh), using the procedures of Boja et al (1992). DAT binding in these limbic areas ( $\mathrm{HC}$ and $\mathrm{pRh}$ ) is quite low, and constitutes a small percentage of total binding (Tohyama and Takatsuji, 1998; Richtand et al, 1995; Donnan et al, 1989). Similarly, serotonin innervation constitutes only about $20 \%$ of the dopaminergic input to the striatum (Brownstein and Palkovits, 1984). For these reasons, only DAT in striatum and SERT in HC and pRh were assessed. For striatal sections, DAT binding was defined as the total amount of [ $\left.{ }^{125} \mathrm{I}\right] \mathrm{RTI}-55$ binding in the presence of the SERT inhibitor, fluoxetine $(100 \mathrm{nM})$. For HC and pRh sections, SERT binding was defined as the total amount of [ $\left.{ }^{125} \mathrm{I}\right] \mathrm{RTI}$ 55 binding. Slides containing tissue sections and standard slides containing known amounts of radioactivity were apposed to RayMax $\beta$ autoradiography film (ICN Pharmaceuticals) for at least $48 \mathrm{~h}$ before development. Quantification of $\left[{ }^{125}\right.$ I]RTI-55 binding to DAT and SERT in the autoradiographs was carried out on an MCID image analyzer (Imaging Research, St Catherines, Ontario). Image densities were converted to [ ${ }^{125}$ I]RTI-55 binding levels using a calibration curve based on readings taken from images of the standard slides packed with each film. Hippocampal and pRh SERT and striatal DAT levels were determined by outlining these structures (based on Paxinos and Watson, 1998) on their respective $\left[{ }^{125}\right.$ I]RTI-55 images. The regions were quantified for the left and right sides, and readings were averaged from at least three sections per animal. The HC and pRh were chosen because of their known involvement in tasks of learning and memory including OR (see reviews by Squire and Zola-Morgan, 1991; Brown and Aggleton, 2001).

\section{Statistical Analysis}

Temperature data, OR EQs, and $\left[{ }^{125} \mathrm{I}\right] \mathrm{RTI}-55$ binding densities were analyzed using analysis of variance (ANOVA).
Post hoc comparisons of EQs between FAM and STM sessions within the same group were made with pairedsamples $t$-tests. In cases where more than one treatment group was compared with the other groups, significant main effects were explored post hoc with a Bonferroni correction. Correlations between EQ scores during OR testing and transporter-binding densities were investigated using Pearson $r$ r. $P$ values less than 0.05 were considered to indicate statistical significance.

\section{RESULTS}

\section{Experiment 1-ED Plus Binge mAMPH Administration}

Body temperature. Regardless of pretreatment, treatment with $\mathrm{mAMPH}$ on day 14 significantly altered the animals' core body temperatures (Figure 1a), with a significant effect of group (repeated measures ANOVA, $\mathrm{F}_{(3,43)}=12.51$, $p<0.001)$ and time $\left(\mathrm{F}_{(3,129)}=7.39, p<0.001\right)$. Bonferroni post hoc analyses revealed that pretreatment with SAL did not affect animals' hyperthermic response to $\mathrm{mAMPH}$ on the binge administration day (SA/MA $v s$ mAMPH binge, $p>0.05)$. However, pretreatment with mAMPH blunted animals' mAMPH-induced increase in core temperature, such that average body temperatures of the MA/MA group were significantly different from mAMPH binge (MA/MA $v s$ mAMPH binge; $p<0.05$ ), and showed a trend towards a difference from SA/MA-treated animals (MA/MA $v s$ SA/MA; $p=0.08)$.

Object recognition. To investigate the behavioral effects of single-day MAMPH, animals were tested for OR 1 week after mAMPH or SAL binge administration. An analysis of each of the groups' object exploration during the FAM phase of the OR task revealed no differences in either the groups' total exploration of the two identical objects (one-way ANOVA, $\mathrm{F}_{(3,47)}=2.36, p>0.05$; Table 1$)$ or in their preference for either of the two identical objects (Object A1 vs Object A2 paired-samples $t$-test, $p>0.05$ for all three groups).

In the STM test given 90 min later, a novel object replaced one of the familiar objects. A repeated measures ANOVA revealed a significant main effect of test phase (FAM vs STM; $\left.\mathrm{F}_{(1,47)}=41.50, p<0.001\right)$, and a group by phase interaction $\left(\mathrm{F}_{(3,47)}=3.537, p<0.05\right)$. Only SAL binge-treated and MA/MA-treated animals showed significant memory for the familiar object during the STM phase, as evidenced by higher EQ scores during the STM than FAM phase (FAM EQ vs STM EQ, paired samples $t$-tests, $t=3.43 \mathrm{MA} / \mathrm{MA}$; $t=5.79$ SAL binge, $p$ 's $<0.005$ ) (Table 1 ).

DAT and SERT binding. To assess mAMPH-induced damage to the dopaminergic and serotonergic terminals in several brain regions, we used autoradiography to quantify $\left[{ }^{125}\right.$ I]RTI-55 binding to DAT and SERT in the brains of animals tested for OR 1 week after treatment. Specifically, we assessed DAT binding in dorsal $(\mathrm{dCPu})$ and ventral caudate-putamen $(\mathrm{vCPu})$ and nucleus accumbens $(\mathrm{NAc})$, and SERT binding in HC and $\mathrm{pRh}$. A two-way ANOVA of mean monoaminergic transporter binding levels revealed a significant main effect of treatment group (5 (region) $\times 4$ (group) repeated measures ANOVA, $\mathrm{F}_{(3,45)}=6.27, p<0.005$ ) 

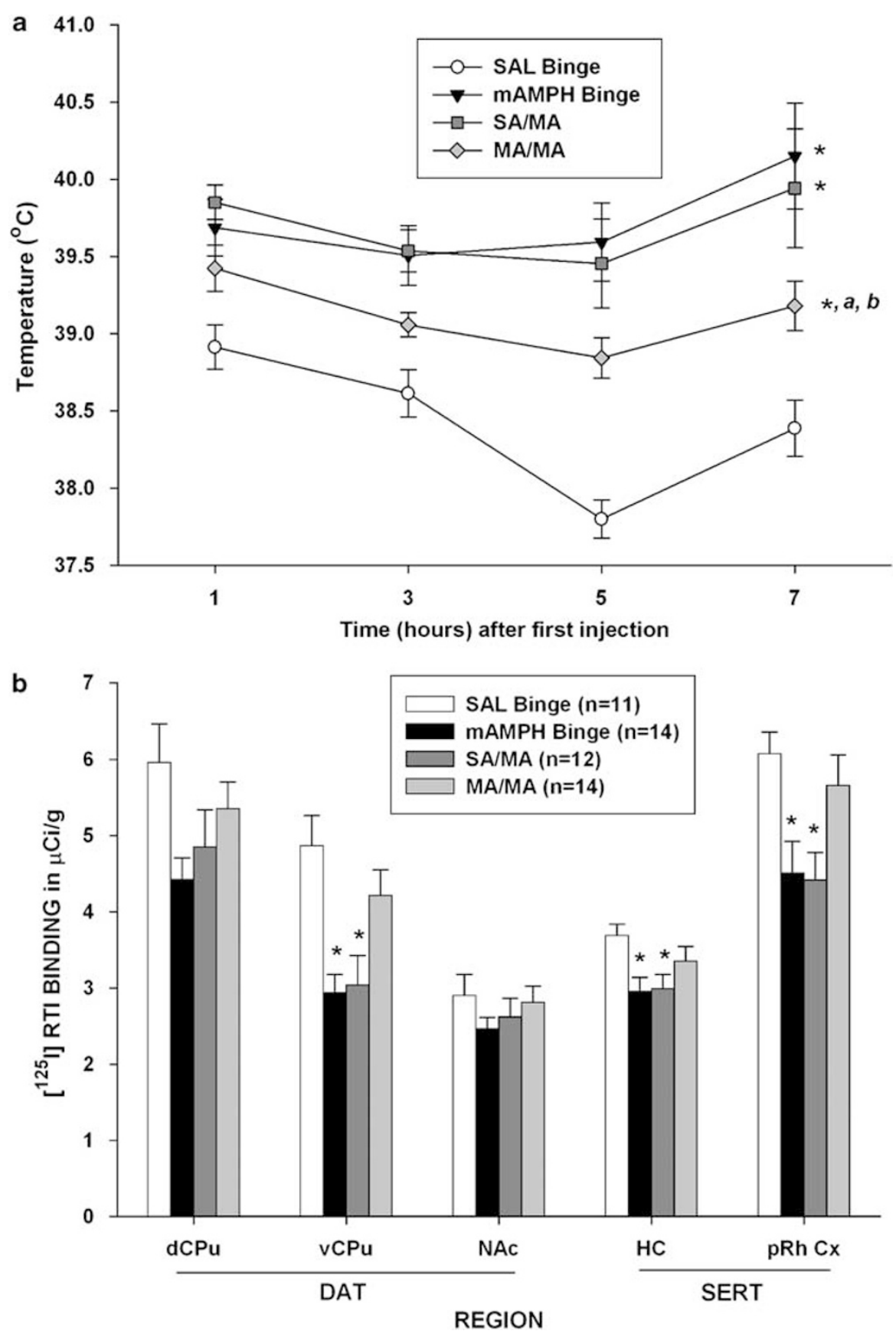

Figure I (a) Core body temperatures (measured I h following each injection). Treatment with four injections of $4 \mathrm{mg} / \mathrm{kg} \mathrm{mAMPH}$ caused significant increases in core body temperature, relative to SAL-injected animals, regardless of pretreatment. However, animals exposed to EDs of mAMPH for I 3 days before the $\mathrm{mAMPH}$ binge day (MA/MA group) showed an attenuated hyperthermic response relative to the animals only given the mAMPH binge (mAMPH binge group). Data are expressed as mean \pm SEM. Mean group temperature (averaged across all four time points) of MA/MA group differs significantly from SAL binge, ${ }^{*} p<0.01$ and from mAMPH binge, ${ }^{a} p<0.05$. Additionally, mean group temperature of group MA/MA showed a trend towards a difference from group SA/MA, ${ }^{b} p=0.08$ (Bonferroni post hoc analysis). (b) $\left[^{125}\right.$ I]RTI-55 binding to dopaminergic transporters in dCPu and vCPu, and NAc, and to serotonergic transporters in $\mathrm{HC}$ and perirhinal cortex ( $\mathrm{pRh} \mathrm{Cx}$ ). One-way ANOVA revealed a significant difference between groups for VCPu DAT, $\mathrm{HC}$, and pRh CXSERT $(p<0.05)$. Indicates significant difference from control (SAL binge), * $p<0.05$ (Dunnett's t-test).

(Figure 1b). Subsequent one-way ANOVAs for each region revealed significant group differences for vCPu DAT and HC and pRh SERT $\left(\mathrm{F}_{(3,47)}=7.39, p<0.001 ; \mathrm{F}_{(3,45)}=3.35\right.$, $p<0.05$; and $\mathrm{F}_{(3,45)}=4.55, p<0.01$, respectively), but not for $\mathrm{dCPu}$ or NAc DAT binding ( $p$ 's $>0.05$ ). Bonferroni post hoc tests revealed that the mAMPH binge regimen induced a significant $40 \%$ depletion in ventral CPu DAT binding, and a significant 20 and $26 \%$ depletion in HC and pRh SERT binding, respectively. The SA/MA group had a loss of monoamine transporter binding $(38,19$, and $27 \%$ depletions of $\left[{ }^{125} \mathrm{I}\right] \mathrm{RTI}-55$ binding to VCPu DAT, HC SERT, and pRh SERT, respectively (Dunnett's post hoc $t$-test, $p<0.01$ for all three regions)) similar to that seen in the mAMPH binge group. There were no significant differences between 
Table I Object Recognition Behavior after Chronic mAMPH Treatments

\begin{tabular}{llll}
\hline Group & FAM EQ & STM EQ & DIFF \\
\hline SAL binge $(N=11)$ & $0.46 \pm 0.03$ & $0.73 \pm 0.05^{\mathrm{a}}$ & $0.28 \pm 0.05$ \\
mAMPH binge $(N=\mid 4)$ & $0.56 \pm 0.04$ & $0.63 \pm 0.05$ & $0.07 \pm 0.04$ \\
SA/MA $(N=12)$ & $0.50 \pm 0.03$ & $0.60 \pm 0.04$ & $0.10 \pm 0.05$ \\
MA/MA $(N=14)$ & $0.51 \pm 0.03$ & $0.66 \pm 0.04^{\mathrm{a}}$ & $0.15 \pm 0.04$ \\
\hline
\end{tabular}

FAM, familiarization phase; DIFF, difference score (STM EQ-FAM EQ); $E Q$, exploration quotient; STM, short-term memory phase. Data expressed as EQ (see Materials and Methods) group mean ( \pm SEM). asignificant difference from FAM EQ, $p<0.01$.

SA/MA and mAMPH binge-treated animals (Bonferroni post hoc, $p$ 's $>0.05$ for all five regions). By contrast, the MA/MA group had no significant decline in DAT or SERT binding, relative to the SAL binge-treated group, for any of the regions analyzed ( $p$ 's $>0.05)$. These data support the observation (Segal et al, 2003) that an ED regimen of mAMPH greatly blunts the neurotoxicity that would otherwise be incurred following a high-dose bingeing regimen of $\mathrm{mAMPH}$. Further, the regional pattern of DAT loss observed in the striatal complex by the mAMPH binge and SA/MA groups (vCPu affected more than $\mathrm{dCPu}$ or NAc) closely mimics the pattern of $\mathrm{mAMPH}$-induced DAT and DA reductions reported by Eisch et al (1992).

Pearson's correlation revealed no significant relationship between animals' performance on the STM phase of the OR task and $\left[{ }^{125} \mathrm{I}\right] \mathrm{RTI}-55$ binding to $\mathrm{dCPu}, \mathrm{vCPu}$, or NAc DAT or to HC or pRh SERT ( $p>0.05$ for all correlations). Also there were no significant correlations between EQ difference scores (STM EQ-FAM EQ) and $\left[{ }^{125} \mathrm{I}\right] \mathrm{RTI}-55$ binding in any region.

\section{Experiment 2-Single-Day mAMPH Administration}

Body temperature. Animals' core body temperatures were measured 1 hour following each of the four MAMPH or SAL injections (Figure 2). Animals given four injections of mAMPH had significant, dose-dependent increases in body temperatures, compared with SAL controls. Repeated measures ANOVA revealed a significant main effect of dose $\left(F_{(4,84)}=93.33, p<0.01\right)$, a significant effect of time point $\left(\mathrm{F}_{(1,84)}=4.35, p<0.05\right)$, and a significant interaction between dose and time $\left(\mathrm{F}_{(4,84)}=7.23, p<0.01\right)$. Bonferroni post hoc analyses revealed that animals treated with $4 \times 3 \mathrm{mg} / \mathrm{kg} \mathrm{mAMPH}$ did not differ in their average body temperatures from animals treated with $4 \times 4 \mathrm{mg} / \mathrm{kg}$ mAMPH, yet both groups differed from all other treatment groups. Additionally, all other treatment groups $(4 \times 2 \mathrm{mg} /$ $\mathrm{kg}, 4 \times 1 \mathrm{mg} / \mathrm{kg}, 4 \times \mathrm{SAL})$ were significantly different from each other $(p$ 's $<0.01)$.

Object recognition. One-way ANOVA revealed that the groups differed significantly in their overall exploration of the two sample objects during the FAM phase of the OR task (the sum of time spent investigating objects A1 and A2; $\left.\mathrm{F}_{(4,86)}=5.18, p<0.01\right)$. Post hoc analyses revealed that this effect was entirely attributable to animals treated with $4 \times 1 \mathrm{mg} / \mathrm{kg} \mathrm{mAMPH}$, who spent a significantly greater amount of time investigating the sample objects (mean \pm $\mathrm{SEM}=41.56 \pm 2.95 \mathrm{~s}$ ) compared with SAL-treated animals $(26 \pm 1.93 \mathrm{~s})$ (Dunnett's $t$-test, $p<0.01)$. No other groups differed significantly from SAL controls on this measure. Additionally, animals in all five groups showed equivalent times investigating the Object $\mathrm{A} 1$ and Object $\mathrm{A} 2$ during the FAM phase (paired-samples $t$-tests, $p$ 's $>0.05$ ).

A repeated measures ANOVA revealed a significant main effect of test phase (FAM EQ vs STM EQ, $\mathrm{F}_{(1,86)}=17.44$, $p<0.01)$, but no significant effects of dosage $\left(\mathrm{F}_{(4,86)}=1.27\right.$, $p=0.29)$ nor a dose by phase interaction $\left(\mathrm{F}_{(4,86)}=1.36\right.$, $p=0.26$; Figure $3 a)$. To determine the source of the significant main effect of test phase observed in the ANOVA, differences between the FAM and STM EQ scores of the individual dosage groups were tested using paired comparisons. SAL controls and animals given four injections of $1 \mathrm{mg} / \mathrm{kg} \mathrm{mAMPH}$ showed a strong preference towards investigating the novel object during the STM test, indicated by an STM EQ score significantly higher than the FAM EQ score ( $t$-test, $t=5.823, p<0.001$ and $t=2.614$, $p<0.05$ for SAL controls and $4 \times 1$ animals, respectively). However, animals given four injections of 2,3 , or $4 \mathrm{mg} / \mathrm{kg}$ mAMPH showed no such STM EQ vs FAM EQ difference, suggesting that prior treatment with these doses of $\mathrm{mAMPH}$ prevented memory retention for the familiar object.

$D A T$ and SERT binding. A 5 (region) $\times 5$ (treatment group) repeated measures ANOVA revealed a significant main effect of dosage group $\left(\mathrm{F}_{(4,86)}=10.18, p<0.001\right)$, brain region $\left(\mathrm{F}_{(4,344)}=199.40, p<0.001\right)$, and a significant interaction between the two variables $\left(\mathrm{F}_{(16,344)}=5.65, p<0.001\right)$ (Figure 3b). Subsequent one-way ANOVAs revealed significant main effects of group for all five regions analyzed $\left(F_{(4,90)}=2.86,12.47,2.54,9.89\right.$, and 10.98, $p$ 's $<0.05$ for $\mathrm{dCPu}, \mathrm{vCPu}, \mathrm{NAc}$ DAT, and $\mathrm{HC}$ and $\mathrm{pRh}$ SERT, respectively). Relative to SAL controls, the $4 \times 4 \mathrm{mg} / \mathrm{kg} \mathrm{mAMPH}$ regimen induced significant loss of DAT binding in $\mathrm{dCPu}$ $(17 \%)$ and $\mathrm{vCPu}(40 \%)$ and of SERT binding in HC (34\%) and pRh (33\%) (Figure 3b) (Dunnett's $t$-tests, $p<0.005$ for all four regions). Animals treated with a $4 \times 3$ regimen of mAMPH had a significant $(25 \%)$ depletion in vCPu DAT $(p<0.001)$, and a significant $(15 \%)$ depletion in $\mathrm{pRh}$ SERT $(p<0.05)$, relative to SAL controls. Additionally, animals treated with four injections of $2 \mathrm{mg} / \mathrm{kg} \mathrm{mAMPH}$ had significant depletions in vCPu DAT $(20 \%)(p<0.05)$. No significant depletions occurred in animals treated with $4 \times 1 \mathrm{mg} / \mathrm{kg} \mathrm{mAMPH}$. These results suggest that increasing doses of mAMPH deplete monoamine transporter content in a graded, regionally dependent manner.

Pearson's correlation was used to investigate the relationship between animals' performance on the STM phase of the OR task and $\left[{ }^{125}\right.$ I]RTI-55 binding to brain monoaminergic transporters after single-day regimens of SAL or differing mAMPH doses (Figure 4). Significant positive correlations were found for STM EQ score and monoaminergic transporter binding in $\mathrm{vCPu} \operatorname{DAT}(r=0.294, p=0.005)$, HC SERT $(r=0.328, p=0.002)$, and pRh SERT $(r=0.308$, $p=0.003)$, but not for NAc or dCPu DAT ( $p$ 's $>0.05)$. Similarly, positive correlations were found between EQ difference scores (STM EQ-FAM EQ) and monoaminergic transporter binding in vCPu DAT $(r=0.228, p=0.029)$, HC 


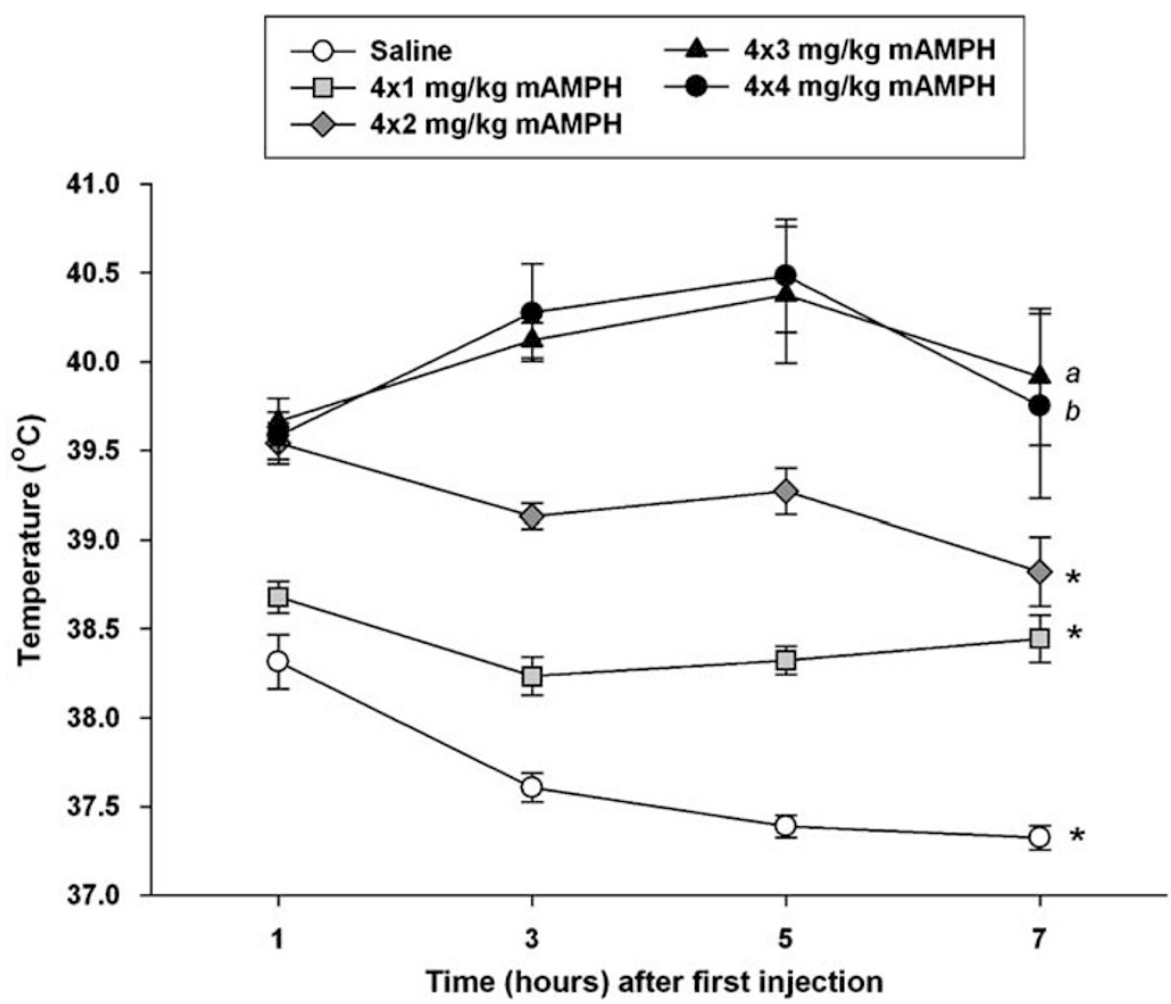

Figure 2 Core body temperatures (measured one hour following each injection). Relative to saline-treated animals, a single-day regimen of mAMPH caused dose-dependent increases in core body temperature, measured I h after each of the four injections. Data expressed as mean \pm SEM. Mean group temperature *differs from all other groups, $p<0.01$, a differs from all groups except $4 \times 4 \mathrm{mg} / \mathrm{kg}, p<0.0 \mathrm{l}$, b differs from all groups except $4 \times 3 \mathrm{mg} / \mathrm{kg}$, $p<0.0$ I (Bonferroni post hoc analysis).

SERT $(r=0.235, p=0.025)$, and pRh SERT $(r=0.217$, $p=0.039)$, but not for NAc or dCPu DAT ( $p$ 's $>0.05)$. These results suggest a relationship between mAMPHinduced depletions of DAT and SERT binding in particular striatal and cortical territories and consequent recognition memory impairments, as assessed by the OR task.

\section{DISCUSSION}

A growing body of evidence indicates that protracted use of mAMPH causes long-term impairments in cognitive function in humans. Clinically, mAMPH users have impairments in motor skills (Volkow et al, 2001; Wang et al, 2004), maintaining attention (Nordahl et al, 2003; Salo et al, 2002), decision-making skills (Rogers et al, 1999; Paulus et al, 2002), and set-shifting abilities (Simon et al, 2002; Ornstein et al, 2000). One particularly prominent feature noted in several studies with human mAMPH users is that of these users' poor recall and recognition memory (Ornstein et al, 2000; Volkow et al, 2001; Sim et al, 2002; Simon et al, 2002; Gonzalez et al, 2004).

Typically, mAMPH users engage in patterns of bingeing that can be mimicked by dosing regimens in experimental animals. The potential for these binge patterns of administration to induce neurotoxicity to monoaminergic terminals was first described by several researchers in the mid to late 1970s (Koda and Gibb, 1973; Seiden et al, 1975; Ellison et al, 1978; Gibb and Kogan, 1979; Hotchkiss et al, 1979). The neurotoxic dosing regimen usually employed by researchers involves giving animals several moderate to high doses of mAMPH spaced across a single day. These administrations produce long-term damage to forebrain monoaminergic terminals (Koda and Gibb, 1973; Hotchkiss and Gibb, 1980; Schmidt et al, 1985; Wagner et al, 1979; Ricaurte et al, 1982; Axt and Molliver, 1991) and degeneration of neuronal cell bodies in parietal cortex (Commins and Seiden, 1986; Eisch et al, 1996; O’Dell and Marshall, 2000).

Additionally, patterns of mAMPH administration that induce neurotoxicity produce deficits in at least two domains of learning and memory: motor learning (Chapman et al, 2001), and novelty preference OR (Bisagno et al, 2002; Schröder et al, 2003; Belcher et al, 2005), findings which may provide analogues to the motor and recognition memory deficits seen in human mAMPH users. However, some researchers have questioned the applicability of such single-day binge paradigms to human self-administration patterns, arguing that a more appropriate model is to expose drug-naïve animals to multiple days of lower EDs of $\mathrm{mAMPH}$ before the binge doses. Importantly, these EDs exert a neuroprotective effect, as the depletions of dopaminergic markers induced by a mAMPH binge are attenuated when it is preceded by several days of EDs of mAMPH (Segal et al, 2003; O’Neil et al, 2006).

Animals exposed to a $\mathrm{mAMPH}$ binge regimen (groups SA/MA and MAMPH binge) showed deficits in OR during the STM phase of the OR task. However, when the binge regimen was preceded by 13 days of EDs of $\mathrm{MAMPH}$ (group MA/MA), no OR impairment was observed. 

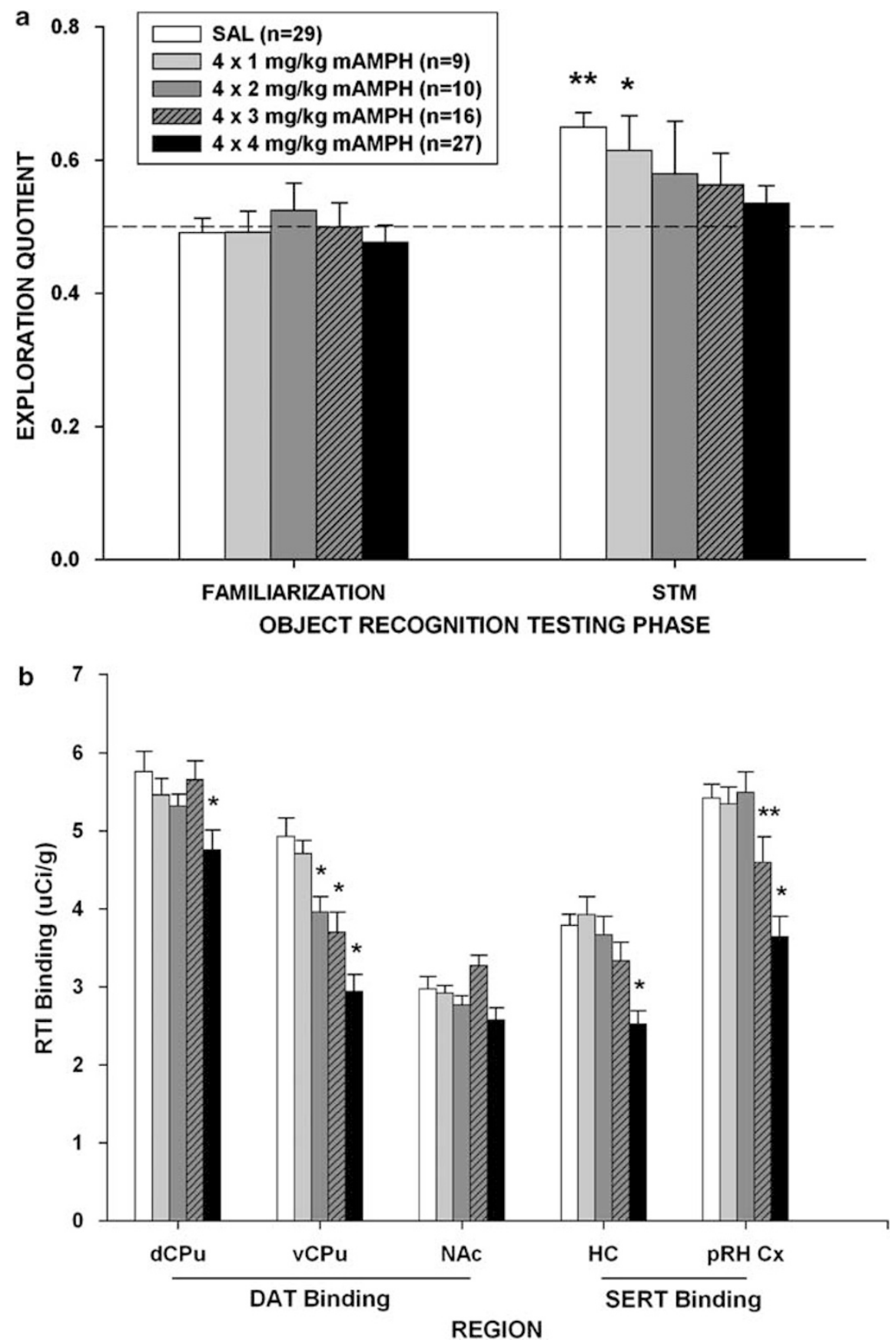

Figure 3 (a) EQs during familiarization and STM phases of animals given four injections of mAMPH or saline in a single day. Four injections of 2, 3, or 4 mg/ $\mathrm{kg}$ mAMPH impair STM performance in the novel OR memory task I week after drug treatment. Data are expressed as mean \pm SEM. Significant withingroup difference between the two phases (Student's paired-samples t-test) are indicated by $* p<0.05$, *** $<0.01$. Dashed line represents chance performance. (b) [125/]RTI-55 binding to dopaminergic transporters in dCPu and vCPu and NAc, and to serotonergic transporters in HC and pRh Cx. Values represent mean \pm SEM binding values, expressed as $\mu \mathrm{Ci}$ per gram of tissue. Dunnett's $t$-tests, differs significantly from saline-treated group, * $p<0.0 \mathrm{l}$, *** $p<0.05$.

The ED plus binge regimen of mAMPH also resulted in monoamine transporter binding levels that differed from those produced by single-day binge mAMPH. Whereas both SA/MA and mAMPH binge groups from the first experiment experienced significant reductions in striatal DAT and hippocampal and perirhinal SERT binding levels compared with SA/SA controls, the levels of DAT and SERT were not significantly different between groups MA/MA and SAL controls. In addition to attenuating the binge mAMPH- induced behavioral impairments and monoamine transporter depletions, the ED schedule of mAMPH attenuated the acute hyperthermic response to binge mAMPH doses. These findings are consistent with earlier reports that treatment with EDs of mAMPH before a binge administration mitigates the hyperthermic response and neurochemical depletions that ensue from mAMPH binge regimens (Segal et al, 2003; O'Neil et al, 2006). These data suggest that EDs of $\mathrm{mAMPH}$ help protect against the monoamine transporter 

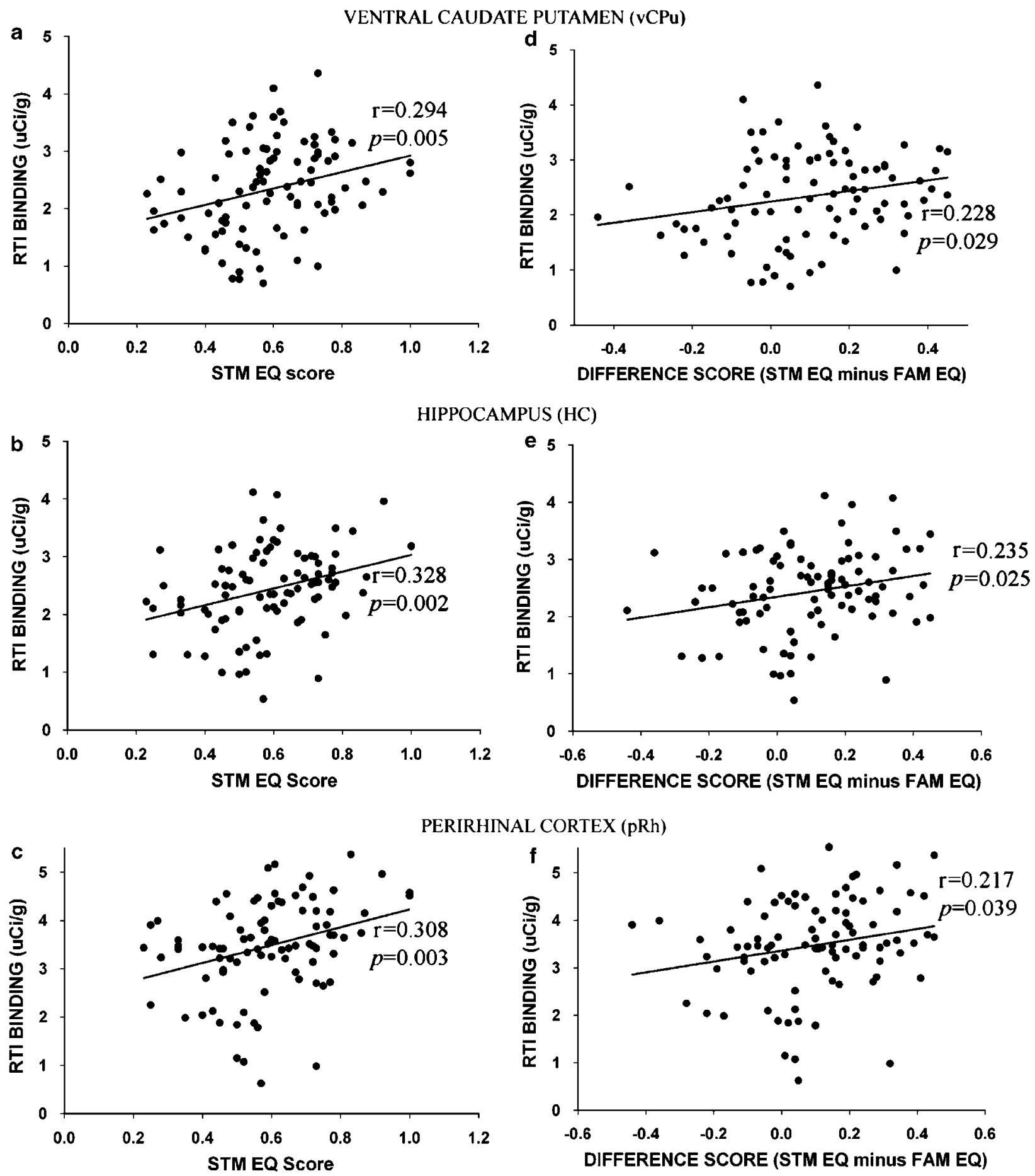

Figure 4 Relationship between transporter-binding density and $\mathrm{OR}$ performance for animals given single-day regimens of either mAMPH or SAL (Experiment 2). Pearson $r$ revealed significant correlations between EQs during the STM phase and [ ${ }^{125}$ I]RTI-55 binding in vCPu (a), HC (b), and pRh (c). Additionally, RTI binding significantly correlated with OR Difference scores (STM EQ-Familiarization phase EQ) for these same brain regions $(d-f)$.

damage that causes cognitive impairments. One caveat to this conclusion is that, in Experiment 1, the correlations between OR impairments and the reductions in monoamine transporter binding were not statistically significant, a result that may have arisen because the animals of that experiment tended to cluster into two categories, depleted or non-depleted.
The second experiment addressed more fully the issue of whether the mAMPH-induced impairments in OR memory co-varied with the extent of the monoamine transporter loss. In that experiment, we attempted to vary the degree of neurotoxicity arising from a single-day mAMPH binge regimen by using a range of $\mathrm{mAMPH}$ doses. In this way, we were able to achieve a wide range of effects on DA and 5-HT 
transporters. Animals given single-day mAMPH bingeing doses that caused neurotoxicity $(4 \times 4,4 \times 3$ and $4 \times 2 \mathrm{mg} /$ $\mathrm{kg}$ ) showed no evidence of STM for the familiar object when tested for OR, while animals given saline or the nonneurotoxic regimen of $\mathrm{mAMPH}(4 \times 1 \mathrm{mg} / \mathrm{kg})$ evidenced memory for the familiar object. Animals given the highest doses of $\mathrm{mAMPH}(4 \times 4 \mathrm{mg} / \mathrm{kg})$ appear to have the most severe impairments in OR (Figure 3a). As animals in the $4 \times 1 \mathrm{mg} / \mathrm{kg} \mathrm{mAMPH}$ group also showed a significantly greater total amount of exploration of the sample objects during the familiarization phase, it is possible that their intact retention during the STM phase was attributable to their enhanced initial exploration of the objects.

Correlational analyses were conducted to further explore the relationship between OR impairments and monoaminergic transporter loss in animals given single-day dosing regimens. Significant positive correlations between OR scores at the STM test (or STM-FAM difference scores) and mean $\left[{ }^{125} \mathrm{I}\right] \mathrm{RTI}-55$ binding to monoaminergic transporters were observed for animals given single-day dosing regimens (Figure 4). These findings support a possible contribution of monoamine terminal injury to the MAMPHinduced decline in recognition memory. These results are consistent with experimental literature indicating that both the HC (Clark et al, 2000; Broadbent et al, 2004) and pRh (Meunier et al, 1993; Turchi et al, 2005; Winters and Bussey, 2005; Warburton et al, 2005) contribute to performance on recognition memory tasks. However, closer inspection of the results from the single-day experiment does not support a simple relationship between OR impairments and reductions in SERT binding in the regions analyzed. For example, animals in the $4 \times 2,4 \times 3$, and $4 \times 4 \mathrm{mg} / \mathrm{kg} \mathrm{mAMPH}$ groups showed poor performance on OR, whereas only animals treated with a $4 \times 4 \mathrm{mg} / \mathrm{kg} \mathrm{mAMPH}$ dosing regimen showed reliable serotonergic depletions. In comparison, the present finding that the single-day mAMPH groups showing reductions in $\mathrm{vCPu}$ DAT did correspond to those displaying OR impairments accords with human imaging research pointing to correlations between striatal dopaminergic processes and the cognitive impairments of mAMPH users. Volkow et al (2001) found that performance on verbal memory tasks in detoxified human mAMPH abusers correlates with the extent of striatal DAT availability. Additionally, these results agree with findings from $\mathrm{He}$ et al (2006) that demonstrate a positive correlation between striatal dopaminergic integrity and OR performance in rats previously exposed to neurotoxic regimens of $\mathrm{mAMPH}$. Establishing a causal relationship between any single aspect of the neurotoxicity and the OR impairments, however, remains challenging.

Much prior research indicates that a binge $\mathrm{mAMPH}$ regimen exposes both monoamine and select cortical neuron populations to a combination of intra- and extracellular factors (eg, Lavoie and Hastings, 1999; Mark et al, 2004) that promote their injury. A period of escalating mAMPH dosing appears to attenuate both the acute effects (hyperthermia) and the enduring effects (recognition memory impairments, monoamine transporter loss) exerted by later binge mAMPH administration. O'Neil et al (2006) analyzed the basis for the influences of an escalating mAMPH dosing regimen on the hyperthermia and DA efflux induced by mAMPH binge, demonstrating that the
ED had no effect on concentrations of mAMPH or AMPH in brain or plasma during the binge. Several decades of research have shown that environmental context and past drug history interact to modulate the effects of amphetamines (see Badiani and Robinson (2004) for a comprehensive review). Arguably, the neuroprotective effect of the escalating $\mathrm{mAMPH}$ regimen could be mediated by contextual cues serving to produce tolerance to the neurotoxic effects of the binge mAMPH. However, the fact that the ED regimen and the subsequent binge regimen were each administered in separate chambers and rooms makes this argument unlikely. While the ED regimen appears to induce a general pharmacodynamic tolerance to subsequent binge mAMPH effects (O'Neil et al, 2006), including its neurotoxic and cognitive consequences, the dependence of the recognition memory impairments on the monoamine transporter loss remains uncertain.

Although the principal findings of these experiments point in the direction of a correspondence between the monoamine injury and OR impairments, other findings suggest dissociations. First, administration of $d$-amphetamine or $p$-chloroamphetamine, which produce selective reductions in DAT or SERT, respectively, did not result in OR impairments, suggesting that injury to neither monoamine alone suffices to explain mAMPH's effects on this cognitive task (Belcher et al, 2005). Second, and more telling, mAMPH or $d$-AMPH, when administered in nonneurotoxic sensitizing regimens, can produce impairments in OR (Belcher et al, 2006; Bisagno et al, 2003). These latter findings raise the possibility that factors other than neural injury can cause OR memory deficits in mAMPH-treated animals. Specifically, binge dosing regimens may limit later memory abilities because of the injury they cause (Schröder et al, 2003; Belcher et al, 2005), whereas a sensitizing mAMPH dose regimen may produce subsequent impairments in cognitive function by interfering with neural plasticity mechanisms (Kolb et al, 2003) that contribute to the learning and retention of new information (Briand et al, 2005; Belcher et al, 2006). However, even neurotoxic mAMPH regimens may impair cognitive function, at least in part, by inducing sensitization (Itzhak et al, 2002). While the cellular mechanisms underlying these effects of $\mathrm{mAMPH}$ are presently unknown, other research has implicated both hippocampal brain-dervied neurotrophic factor (Heldt et al, 2007) and phosphorylated extracellular signal-regulated kinase (pERK; Kelly et al, 2003) in OR memory. Thus, a possible downregulation of the tyrosine kinase-ERK signaling pathway in mAMPH-treated animals warrants consideration.

In summary, we have demonstrated that memory loss due to administration of single-day neurotoxic binge $\mathrm{mAMPH}$ can be prevented with prior exposure to several days of neuroprotective EDs of mAMPH. Additionally, results from single-day treatment with various $\mathrm{mAMPH}$ doses suggest that a threshold of damage may be necessary in order for the cognitive deficits to appear. Taken together, these two pieces of information suggest that monoamine neurotoxicity accounts for the observed cognitive impairments. However, this interpretation needs to be tempered by two findings; (i) amphetamines (other than $\mathrm{mAMPH}$ ) that injure either DA or 5-HT systems do not produce cognitive deficits (Belcher et al, 2005) and (ii) non-neurotoxic 
mAMPH administration can produce cognitive deficits (Belcher et al, 2006). Further studies will be necessary in order to fully elucidate the processes underlying the mAMPH-induced cognitive impairments.

\section{ACKNOWLEDGEMENTS}

This work was supported by PHS awards DA-12204 and DA-4-8849.

\section{DISCLOSURE/CONFLICT OF INTEREST}

The author(s) declare that, except for income received from their primary employer, no financial support or compensation has been received from any individual or corporate entity over the past 3 years for research or professional service and there are no personal financial holdings that could be perceived as constituting a potential conflict of interest.

\section{REFERENCES}

Axt KJ, Molliver ME (1991). Immunocytochemical evidence for methamphetamine-induced serotonergic axon loss in the rat brain. Synapse 9: 302-313.

Badiani A, Robinson TE (2004). Drug-induced neurobehavioral plasticity: the role of environmental context. Behav Pharmacol 15: 327-339.

Belcher AM, O'Dell SJ, Marshall JF (2005). Impaired object recognition memory following methamphetamine, but not $p$-chloroamphetamine- or $d$-amphetamine-induced neurotoxicity. Neuropsychopharmacology 30: 2026-2034.

Belcher AM, O'Dell SJ, Marshall JF (2006). A sensitizing regimen of methamphetamine causes impairments in a novelty preference task of object recognition. Behav Brain Res 170: 167-172.

Bisagno V, Ferguson D, Luine VN (2002). Short toxic methamphetamine schedule impairs object recognition task in male rats. Brain Res 940: 95-101.

Bisagno V, Ferguson D, Luine VN (2003). Chronic D-amphetamine induces sexually dimorphic effects on locomotion, recognition memory, and brain monoamines. Pharmacol Biochem Behav 74: 859-867.

Boja JW, Mitchell WM, Patel A, Kopajtic TA, Carroll FI, Lewin AH et al (1992). High-affinity binding of $\left[{ }^{125} \mathrm{I}\right] \mathrm{RTI}-55$ to dopamine and serotonin transporters in rat brain. Synapse 12: 27-36.

Bowyer JF, Davies DL, Schmued L, Broening HW, Newport GD, Slikker Jr W et al (1994). Further studies of the role of hyperthermia in methamphetamine neurotoxicity. $J$ Pharmacol Exp Ther 268: 1571-1580.

Bowyer JF, Tank AW, Newport GD, Slikker Jr W, Ali SF, Holson RR (1992). The influence of environmental temperature on the transient effects of methamphetamine on dopamine levels and dopamine release in rat striatum. J Pharmacol Exp Ther 260: 817-824.

Briand LA, Robinson TE, Maren S (2005). Enhancement of auditory fear conditioning after housing in a complex environment is attenuated by prior treatment with amphetamine. Learn Mem 12: 553-556.

Broadbent NJ, Squire LR, Clark RE (2004). Spatial memory, recognition memory, and the hippocampus. Proc Natl Acad Sci USA 101: 14515-14520.

Brown MW, Aggleton JP (2001). Recognition memory: what are the roles of the perirhinal cortex and hippocampus? Nat Rev Neurosci 2: 51-61.
Brownstein MJ, Palkovits M (1984). Catecholamines, serotonin, acetylcholine and $\gamma$-aminobutyric acid in the rat brain: biochemical studies. In: Björklund A, Hökfelt T (eds). Handbook of Chemical Neuroanatomy. Elsevier: New York. pp 23-54.

Chapman DE, Hanson GR, Kesner RP, Keefe KA (2001). Long-term changes in basal ganglia function after a neurotoxic regimen of methamphetamine. J Pharmacol Exp Ther 296: 520-527.

Clark RE, Zola SM, Squire LR (2000). Impaired recognition memory in rats after damage to the hippocampus. J Neurosci 20 8853-8860.

Commins DL, Seiden LS (1986). alpha-Methyltyrosine blocks methylamphetamine-induced degeneration in the rat somatosensory cortex. Brain Res 365: 15-20.

Donnan GA, Kaczmarczyk SJ, McKenzie JS, Kalnins RM, Chilco PJ, Mendelsohn FA (1989). Catecholamine uptake sites in mouse brain: distribution determined by quantitative $\left[{ }^{3} \mathrm{H}\right]$ mazindol autoradiography. Brain Res 504: 64-71.

Eisch AJ, Gaffney M, Weihmuller FB, O’Dell SJ, Marshall JF (1992). Striatal subregions are differentially vulnerable to the neurotoxic effects of methamphetamine. Brain Res 598: 321-326.

Eisch AJ, O'Dell SJ, Marshall JF (1996). Striatal and cortical NMDA receptors are altered by a neurotoxic regimen of methamphetamine. Synapse 22: 217-225.

Ellison G, Eison MS, Huberman HS, Daniel F (1978). Long-term changes in dopaminergic innervation of caudate nucleus after continuous amphetamine administration. Science 201: 276-278.

Ennaceur A, Aggleton JP (1997). The effects of neurotoxic lesions of the perirhinal cortex combined to fornix transection on object recognition memory in the rat. Behav Brain Res 88: 181-193.

Ennaceur A, Delacour J (1988). A new one-trial test for neurobiological studies of memory in rats. 1: behavioral data. Behav Brain Res 31: 47-59.

Friedman SD, Castaneda E, Hodge GK (1998). Long-term monoamine depletion, differential recovery, and subtle behavioral impairment following methamphetamine-induced neurotoxicity. Pharmacol Biochem Behav 61: 35-44.

Gibb JW, Kogan FJ (1979). Influence of dopamine synthesis on methamphetamine-induced changes in striatal and adrenal tyrosine hydroxylase activity. Naunyn Schmiedebergs Arch Pharmacol 310: 185-187.

Gonzalez R, Rippeth JD, Carey CL, Heaton RK, Moore DJ, Schweinsburg BC et al (2004). Neurocognitive performance of methamphetamine users discordant for history of marijuana exposure. Drug and Alcohol Dependence 76: 181-190.

He J, Yang Y, Yu Y, Li X, Li X-M (2006). The effects of chronic administration of quetiapine on the methamphetamine-induced recognition memory impairment and dopaminergic terminal deficit in rats. Behav Brain Res 172: 39-45.

Heldt SA, Stanek L, Chhatwal JP, Ressler KJ (2007). Hippocampus-specific deletion of BDNF in adult mice impairs spatial memory and extinction of aversive memories. Mol Psychiatry 12: 656-670.

Hotchkiss AJ, Gibb JW (1980). Long-term effects of multiple doses of methamphetamine on tryptophan hydroxylase and tyrosine hydroxylase activity in rat brain. J Pharmacol Exp Ther 214: 257-262.

Hotchkiss AJ, Morgan ME, Gibb JW (1979). The long-term effects of multiple doses of methamphetamine on neostriatal tryptophan hydroxylase, tyrosine hydroxylase, choline acetyltransferase and glutamate decarboxylase activities. Life Sci 25 1373-1378.

Itzhak Y, Martin JL, Ali SF (2002). Methamphetamine-induced dopaminergic neurotoxicity in mice: Long-lasting sensitization to the locomotor stimulation and desensitization to the rewarding effects of methamphetamine. Prog NeuroPsychopharmacol Biol Psychiatry 26: 1177-1183.

Kelly A, Laroche S, Davis S (2003). Activation of mitogen-activated protein kinase/extracellular signal-regulated kinase in hippocampal 
circuitry is required for consolidation and reconsolidation of recognition memory. J Neurosci 23: 5354-5360.

Koda LY, Gibb JW (1973). Adrenal and striatal tyrosine hydroxylase activity after methamphetamine. J Pharmacol Exp Ther 185: 42-48.

Kolb B, Gorny G, Li Y, Samaha AN, Robinson TE (2003). Amphetamine or cocaine limits the ability of later experience to promote structural plasticity in the neocortex and nucleus accumbens. Proc Nalt Acad Sci USA 100: 10523-10528.

Lavoie MJ, Hastings TG (1999). Dopamine quinone formation and protein modification associated with the striatal neurotoxicity of methamphetamine: evidence against a role for extracellular dopamine. J Neurosci 19: 1484-1491.

Mark KA, Soghomonian JJ, Yamamoto BK (2004). High-dose methamphetamine acutely activates the striatonigral pathway to increase striatal glutamate and mediate long-term dopamine toxicity. J Neurosci 24: 11449-11456.

Meunier M, Bachevalier J, Mishkin M, Murray EA (1993). Effects on visual recognition of combined and separate ablations of the entorhinal and perirhinal cortex in rhesus monkeys. $J$ Neurosci 13: $5418-5432$.

Mumby DG, Gaskin S, Glenn MJ, Schramek TE, Lehmann H (2002). Hippocampal damage and exploratory preferences in rats: memory for objects, places, and contexts. Learn Mem 9: 49-57.

Nordahl TE, Salo R, Leamon M (2003). High-dose methamphetamine acutely activates the striatonigral pathway to increase striatal glutamate and mediate long-term dopamine toxicity. J Neurosci 24: 11449-11456.

O’Neil ML, Kuczenski R, Segal DS, Cho AK, Lacan G, Melega WP (2006). Escalating dose pretreatment induces pharmacodynamic and not pharmacokinetic tolerance to a subsequent high-dose methamphetamine binge. Synapse 60: 465-473.

O’Dell SJ, Marshall JF (2000). Repeated administration of methamphetamine damages cells in the somatosensory cortex: overlap with cytochrome oxidase-rich barrels. Synapse 37: $32-37$.

Ornstein TJ, Iddon JL, Baldacchino AM, Sahakian BJ, London M, Everitt BJ. et al (2000). Profiles of cognitive dysfunction in chronic amphetamine and heroin abusers. Neuropsychopharmacology 23: 113-126.

Paulus MP, Hozack NE, Zauscher BE, Frank L, Brown CG, Braff DL et al (2002). Behavioral and functional neuroimaging evidence for prefrontal dysfunction in methamphetamine-dependent subjects. Neuropsychopharmacology 26: 53-63.

Paxinos G, Watson C (1998). The Rat Brain in Stereotaxic Coordinates. Academic Press: San Diego.

Ricaurte GA, Guillery RW, Seiden LS, Schuster CR, Moore RY (1982). Dopamine nerve terminal degeneration produced by high doses of methylamphetamine in the rat brain. Brain Res 235: 93-103.

Ricaurte GA, Schuster CR, Seiden LS (1980). Long-term effects of repeated methylamphetamine administration on dopamine and serotonin neurons in the rat brain: a regional study. Brain Res 193: 153-163.

Richtand NM, Kelsoe JR, Segal DS, Kuczenski R (1995). Regional quantification of dopamine transporter mRNA in rat brain using a ribonuclease protection assay. Neurosci Lett 200: 73-76.

Rogers RD, Everitt BJ, Baldacchino A, Blackshaw AJ, Swainson R, Wynne $\mathrm{K}$ et al (1999). Dissociable deficits in the decision- making cognition of chronic amphetamine abusers, opiate abusers, patients with focal damage to prefrontal cortex, and tryptophan-depleted normal volunteers: evidence for monoaminergic mechanisms. Neuropsychopharmacology 20: 322-339.

Salo R, Nordahl TE, Possin K, Leamon M, Gibson DR, Galloway GP et al (2002). Preliminary evidence of reduced cognitive inhibition in methamphetamine-dependent individuals. Psychiatry Res 111: 65-74.

Schmidt CJ, Ritter JK, Sonsalla PK, Hanson GR, Gibb JW (1985). Role of dopamine in the neurotoxic effects of methamphetamine. J Pharmacol Exp Ther 233: 539-544.

Schröder N, O'Dell SJ, Marshall JF (2003). Neurotoxic methamphetamine regimen severely impairs recognition memory in rats. Synapse 49: 89-96.

Segal DS, Kuczenski R, O'Neil ML, Melega WP, Cho AK (2003). Escalating dose methamphetamine pretreatment alters the behavioral and neurochemical profiles associated with exposure to a high-dose methamphetamine binge. Neuropsychopharmacology 28: 1730-1740.

Seiden LS, MacPhail RC, Oglesby MW (1975). Catecholamines and drug-behavior interactions. Fed Proc 34: 1823-1831.

Simon SL, Domier CP, Sim T, Richardson K, Rawson RA, Ling W (2002). Cognitive performance of current methamphetamine and cocaine abusers. J Addict Disord 21: 61-74.

Sim T, Simon SL, Domier CP, Richardson K, Rawson RA, Ling W (2002). Cognitive deficits among methamphetamine users with attention deficit hyperactivity disorder symptomatology. $J$ Addict Dis 21: 75-89.

Squire LR, Zola-Morgan S (1991). The medial temporal lobe memory system. Science 253: 1380-1386.

Thompson PM, Hayashi KM, Simon SL, Geaga JA, Hong MS, Sui Y et al (2004). Structural abnormalities in the brains of human subjects who use methamphetamine. J Neurosci 24: 6028-6036.

Tohyama M, Takatsuji K (1998). Atlas of Neuroactive Substances and Their Receptors in the Rat. Oxford University Press: New York, NY.

Turchi J, Saunders RC, Mishkin M (2005). Effects of cholinergic deafferentation of the rhinal cortex on visual recognition memory in monkeys. Proc Natl Acad Sci USA 102: 2158-2161.

Volkow ND, Chang L, Wang GJ, Fowler JS, Leonido-Yee M, Franceschi D et al (2001). Association of dopamine transporter reduction with psychomotor impairment in methamphetamine abusers. Am J Psychiatry 158: 377-382.

Wagner GC, Seiden LS, Schuster CR (1979). Methamphetamineinduced changes in brain catecholamines in rats and guinea pigs. Drug and Alcohol Dependence 4: 435-438.

Walsh SL, Wagner GC (1992). Motor impairments after methamphetamine-induced neurotoxicity in the rat. J Pharmacol Exp Ther 263: 617-626.

Wang GJ, Volkow ND, Chang L, Miller E, Sedler M, Hitzemann R et al (2004). Preliminary evidence of reduced cognitive inhibition in methamphetamine-dependent individuals. $\mathrm{Am} \mathrm{J}$ Psychiatry 161: 242-248.

Warburton EC, Glover CP, Massey PV, Wan H, Johnson B, Bienemann A et al (2005). cAMP responsive element-binding protein phosphorylation is necessary for perirhinal long-term potentiation and recognition memory. J Neurosci 25: 6296-6303.

Winters BD, Bussey TJ (2005). Glutamate receptors in perirhinal cortex mediate encoding, retrieval, and consolidation of object recognition memory. J Neurosci 25: 4243-4251. 